Industrial Health, 1981, 19, 223-230.

\title{
CADMIUM, COPPER AND ZINC IN THE URINE OF WELDERS USING CADMIUM-CONTAINING SILVER SOLDER
}

\author{
Yasutomo SUZUKI, Kouichi TODA*, Shinya KOIKE* \\ and Hiroshi YOSHIKAWA** \\ National Institute of Industrial Health, Nagao 6-chome, \\ Tama-ku, Kawasaki 213, Japan \\ *Kanagawa Health Service Association, Nihon Ohdohri \\ 58, Naka-ku, Yokohama 231, Japan \\ **Department of Public Health, Gifu University School \\ of Medicine, Tsukasamachi, Gifu 500, Japan
}

(Received July 3, 1981)

\begin{abstract}
The urinary concentration of cadmium, copper and zinc was determined in 12 male workers who had been engaged in welding work with cadmiumcontaining silver solder. Sephadex chromatographic analysis for these urinary metals was performed in two workers suspected of suffering cadmium-induced renal injury. The mean values of the cadmium, copper and zinc concentrations in the urine of the welders were about $26,2.4$ and 2.6 times the control values, respectively. A linear relationship was obtained between the urinary concentrations of cadmium and both copper and zinc. The chromatographic distribution of these urinary metals in the welders showed that the metallothionein fraction contained cadmium and copper, but not zinc. The copper content of this fraction was much larger than the cadmium content. The cadmium and copper in this fraction represented about $6 \%$ and $10 \%$ of the respective total amounts of these metals in the urine. The remaining cadmium and copper were recovered from the high molecular weight protein fraction and low molecular weight nonprotein fraction. The urinary zinc was recovered from both these fractions. The zinc in the latter fraction represented $85 \%$ of the total urinary zinc.

The present results suggest that cadmium accumulation affects the excretion of copper and zinc in the urine, and that the urinary excretion of metallothionein containing cadmiun as well as copper may be involved in cadmium induced renal injury.
\end{abstract}

Keywords : Cadmium-exposed workers-Kidney damage-Urinary excretion-CadmiumCopper-Zinc-Metallothionein

\section{INTRODUCTION}

It has been reported that cadmium exposure increases the urinary excretion of copper and zinc as well as cadmium in experimental animals ${ }^{1,2)}$. In cadmium-injected rats $^{3,4)}$ 


\section{Y. SUZUKI, K. TODA, S. KOIKE AND H. YOSHIKAWA}

and mice $^{5)}$, metallothionein has been shown to be excreted in the urine. Urinary metallothionein was associated with only copper in cadmium-exposed rats before renal lesions occurred, and with both copper and cadmium after the onset of renal lesions ${ }^{2,6}$.

Many reports ${ }^{7-9)}$ have dealt with the urinary excretion of cadmium in humans exposed to cadmium, but few invstigators have described the cadmium effects on the urinary excretion of copper and zinc. Kono et al. ${ }^{10)}$ reported that increased excretion of urinary copper was observed in inhabitants of distincts polluted with cadmium. Recently, Chang et al. ${ }^{11)}$ demonstrated the urinary excretion of metallothionein in cadmium-exposed workers by radioimmunoassay. However, the binding metals of human urinary metallothionein remain unclear.

We examined urine from workers who had been engaged in welding work using cadmium-containing silver solder for many years. The present paper describes their urinary excretion of cadmium, copper and zinc. The gel chromatographic distribution of these urinary metals is also described.

\section{MAterials AND Methods}

\section{Urine Samples}

The urine of 12 male welders and 5 control subjects was examined. The welders were 20 to 50 years old and had been engaged in welding work with cadmium-containing silver solder for 3 to 23 years. The present examination was performed at about one year after the cessation of use of this kind of silver solder. The urine of the welders was collected during one 24-hour period. The urine was pooled individually and ice-cooled.

The control subjects worked for our institute and had not been exposed to cadmium at higher than usual levels. Their ages were in the same range as those of the welders. The urine of the control subjects was collected before the start of their work in the morning.

\section{Analysis for Urinary Metals}

Aliquots $(100 \mathrm{~m} l)$ of the urine samples were digested in $\mathrm{H}_{2} \mathrm{SO}_{4}$ and $\mathrm{H}_{2} \mathrm{O}_{2}$ in Kjeldahl flasks on a hot plate. The cadmium, copper and zinc contents of the digestant were determined by atomic absorption spectrophotometry after solvent extraction with sodium diethyl dithiocarbamate and MIBK. The analytical method used was essentially the same as that described by Berman ${ }^{12)}$.

\section{Gel Chromatography}

Aliquots $(100 \mathrm{~m} l)$ of the urine samples from two welders were concentrated by ultrafiltration with UM-2 (Amicon) up to about $10 \mathrm{ml}$ at $4^{\circ} \mathrm{C}$. These welders had been engaged in the above-described welding work for about 4 and 23 years, and were suspected of suffering from cadmium-induced renal injury as discussed later. Urine $(100 \mathrm{~m} l)$ from one of the control subjects was also concentrated by the same method. These concen- 


\section{$\mathrm{Cd}, \mathrm{Cu}$ AND $\mathrm{Zn}$ IN URINE OF WELDERS}

trated urine preparations were separated by column chromatography using Sephadex G-75. The elution fractions $(4 \mathrm{~m} l)$ were subjected to UV-absorption measurements $(280$ $\mathrm{nm}$ ) and metal analysis for cadmium, copper and zinc. The chromatography and analytical methods employed were the same as those described previously ${ }^{2}$.

After completion of these analytical procedures, the elution fractions were divided into three groups: high molecular weight protein fraction (fraction Nos. 22-40), metallothionein fraction (fraction Nos. 41-55), and low molecular weight nonprotein fraction (fraction Nos. 56-80). A $2 \mathrm{~m} l$ aliquot from the remaining eluate in each tube was pooled in each group. The pooled samples were reanalzed for cadmium, copper and zinc by the solvent extraction method described above.

\section{RESULTS}

\section{Urinary Metal Concentration}

Fig. 1 shows the cadmium, copper and zinc concentrations in the urine samples of the welders and control subjects. The cadmium concentration in the urine of the welders was much higher than that in the controls. The concentrations of both copper and zinc in the urine of the welders were also higher than those in the controls. The mean values of the copper and zinc concentrations in the welders were two to three times the control values. As shown in Fig. 2, a linear relationship existed between the cadmium concentration and both the copper and zinc concentrations in the urine.
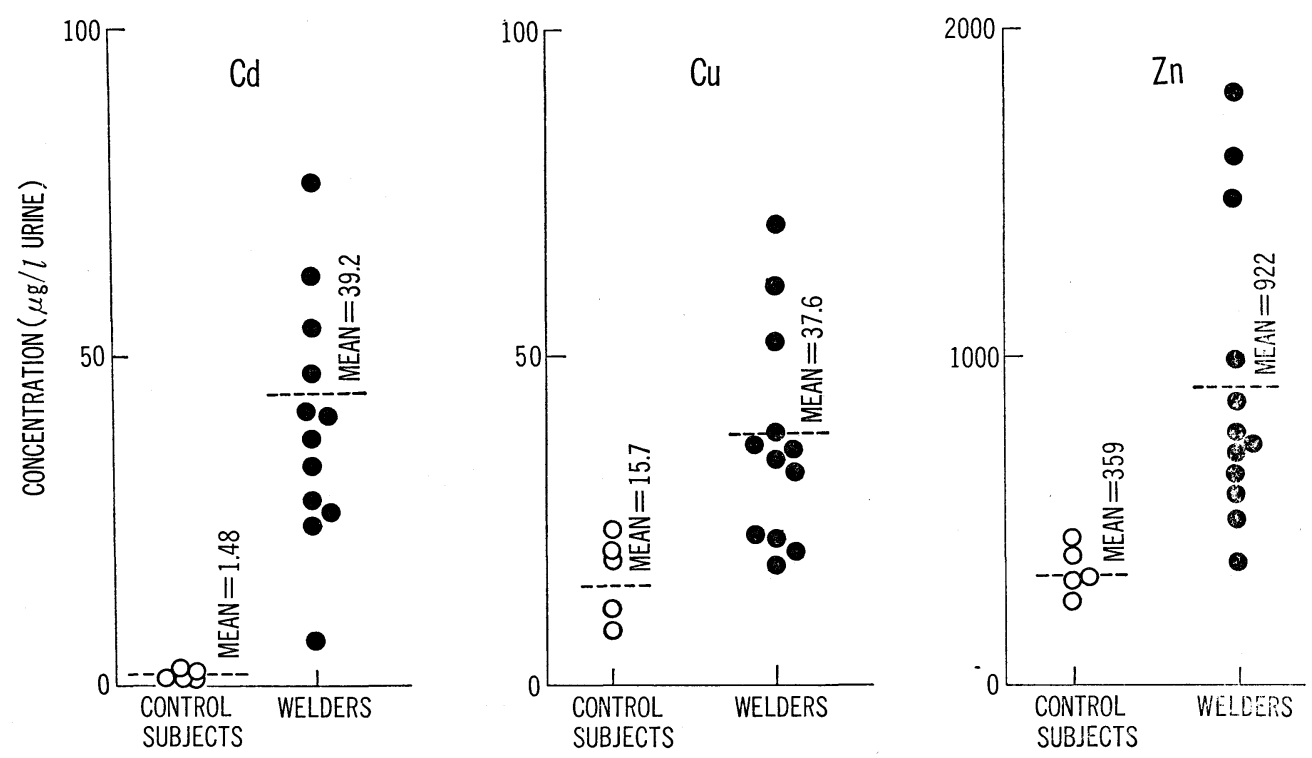

Fig. 1. Cadmium, copper and zinc concentrations in the urine of control subjects and of workers who had been engaged in welding work using cadmium-containing silver solder for 3 to 23 years. 


\section{Y. SUZUKI, K. TODA, S. KOIKE AND H. YOSHIKAWA}

: WELDER, O : CONTROL

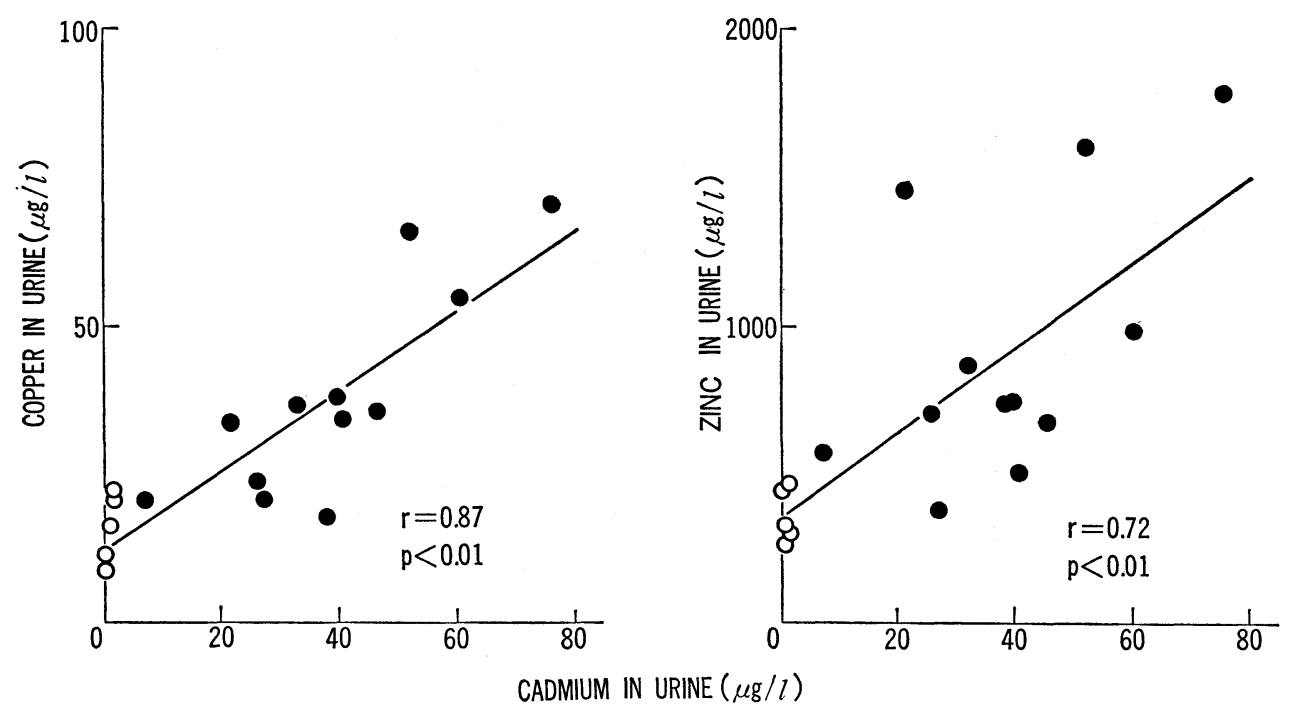

Fig. 2. Relationship between urinary concentrations of cadmium and copper or zinc in silver-solder welders and control subjects.

\section{Gel Chromatographic Distribution of Urinary Metals}

As mentioned, urine samples from one control subject and two welders were separated by Sephadex chromatography. Fig. 3 shows the gel filtration profile of the control specimen. A high absorbance at $280 \mathrm{~nm}$ was observed in both the high molecular weight protein fraction (HM-F) near the void volume of the column and the low molecular weight nonprotein fraction (LM-F) near the bed volume. The absorption peak in HM-F may be due to urinary proteins of high molecular weights. The extremely high absorbance in LM-F may be due to some urinary nonprotein constituents.

Urinary cadmium, copper and zinc appeared in HM-F and LM-F, but none of these metals were detected in the metallothionein fraction (MT-F) in the control urine. As can be seen from Table 1, most of the urinary cadmium (55\%) and zinc (94\%) was recovered from LM-F.

Fig. 4 shows a separation profile of urine from one of the welders. Two clear peaks of UV-absorbance were observed in the elution regions of urinary proteins. One was observed in HM-F : this peak was much higher than the corresponding one in the control urine. The other was observed in the fractions 42 to 48 , which were identical to the elution fractions of proteins having molecular weights of 10,000 to 15,000 .

Metal analysis of the elution fractions revealed that urinary metals were distributed in $\mathrm{HM}-\mathrm{F}, \mathrm{MT}-\mathrm{F}$ and $\mathrm{LM}-\mathrm{F}$ in the urine of this welder. MT-F contained cadmium, copper, but no zinc, while both of the other two fractions contained cadmium, copper and zinc. The cadmium content of MT-F was very small and the copper in this fraction was apparently greater than the cadmium as shown in Table 2. Almost equal amounts 
$\mathrm{Cd}, \mathrm{Cu}$ AND $\mathrm{Zn}$ IN URINE OF WELDERS

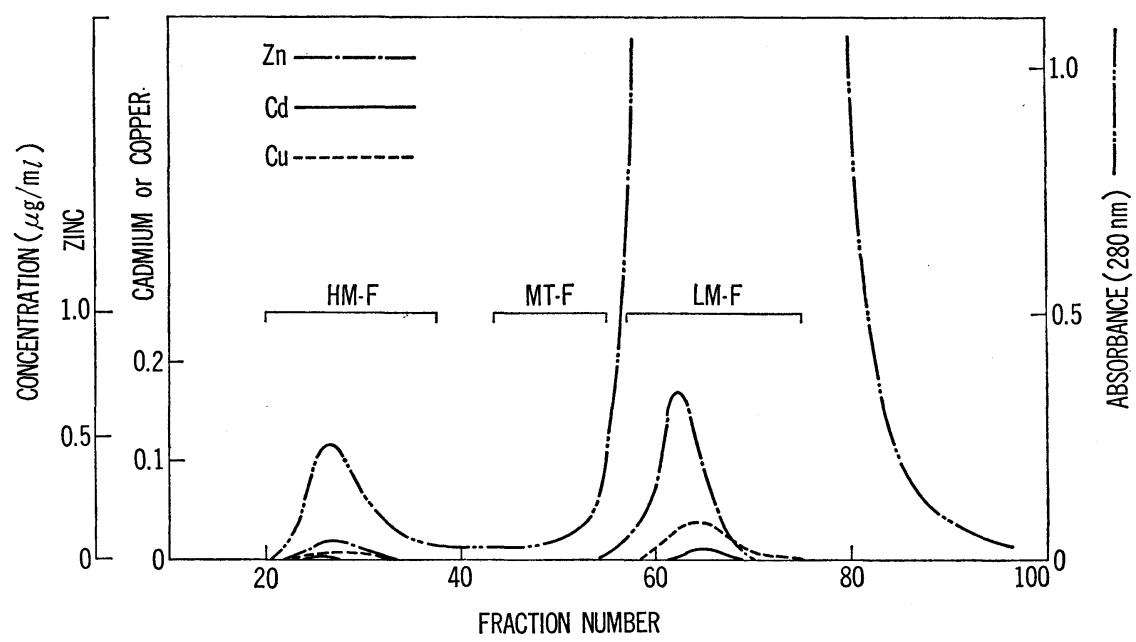

Fig. 3. Sephadex G-75 separation profile of urine from a normal subject. The urine $(100 \mathrm{~m} l)$ was concentrated by ultrafiltration with $\mathrm{UM}-2$ up to about $10 \mathrm{~m} l$. The concentrated urine sample was filtrated on a Sephadex column $(2.6 \times 50 \mathrm{~cm})$ with $0.05 \mathrm{M} \mathrm{NaCl}$ and $0.01 \mathrm{M}$ Tris- $\mathrm{HCl}$ buffer, $\mathrm{pH} 8.6$, containing $0.02 \%$ sodium azide at a speed of $20 \mathrm{ml} / \mathrm{hr}$, and $4 \mathrm{~m} l$ fractions were collected.

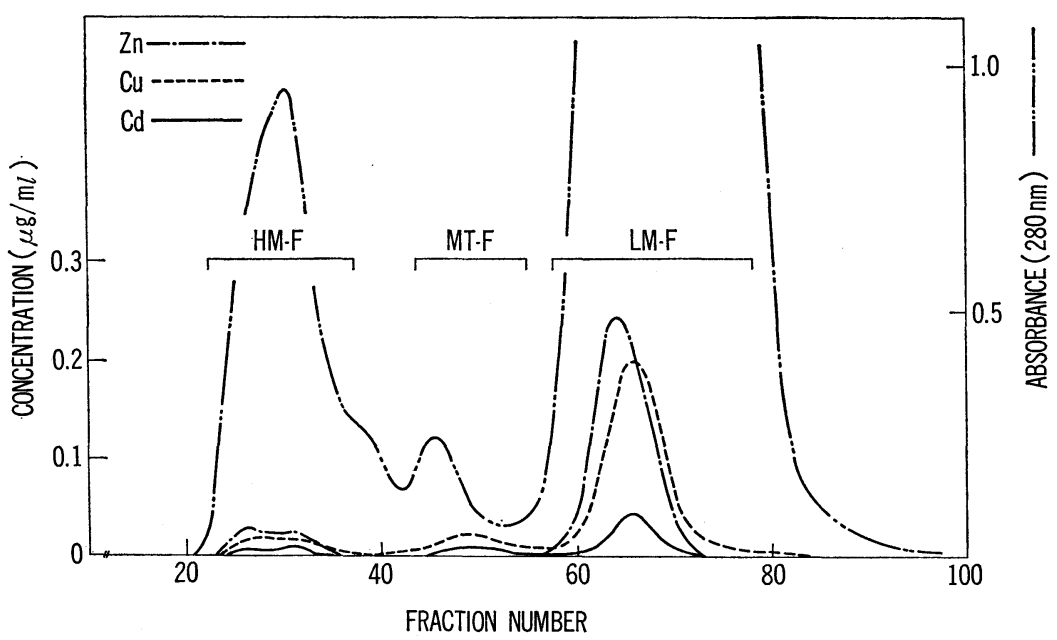

Fig. 4. Sephadex G-75 separation profile of urine from a worker who had been engaged in welding work using cadmium-containing silver solder for about 23 years. The urine $(100 \mathrm{~m} l)$ was concentrated by ultrafiltration with UM-2 up to about $10 \mathrm{~m} l$. The concentrated urine sample was filtrated on a Sephadex column $(2.6 \times 50 \mathrm{~cm})$ with $0.05 \mathrm{M} \mathrm{NaCl}$ and $0.01 \mathrm{M}$ Tris$\mathrm{HCl}$ buffer, $\mathrm{pH} 8.6$, containing $0.02 \%$ sodium azide at a speed of 20 $\mathrm{m} l / \mathrm{hr}$, and $4 \mathrm{~m} l$ fractions were collected. 


\section{Y. SUZUKI, K. TODA, S. KOIKE AND H. YOSHIKAWA}

Table 1. Sephadex chromatographic distribution of urinary metals in a normal subject.

\begin{tabular}{|c|c|c|c|c|c|c|}
\hline \multirow{2}{*}{ Metals } & \multicolumn{2}{|c|}{$\mathrm{HM}-\mathrm{F}$} & \multicolumn{2}{|c|}{ MT-F } & \multicolumn{2}{|c|}{ LM-F } \\
\hline & $(\mu \mathrm{g})$ & $(\%)$ & $(\mu \mathrm{g})$ & $(\%)$ & $(\mu \mathrm{g})$ & (\%) \\
\hline $\mathrm{Cd}$ & 0.100 & 45.5 & n.d. & - & 0.120 & 54.5 \\
\hline $\mathrm{Cu}$ & 0.171 & 16.3 & n.d. & - & 0.880 & 83.7 \\
\hline $\mathrm{Zn}$ & 1.18 & 6.1 & n.d. & - & 18.3 & 93.9 \\
\hline
\end{tabular}

HM-F : High molecular weight protein fraction.

MT-F : Metallothionein fraction.

LM-F : Low molecular weight nonprotein fraction.

n.d. : None detected.

Table 2. Sephadex chromatographic distribution of urinary metals in a silver-solder welder.

\begin{tabular}{|c|c|c|c|c|c|c|}
\hline \multirow{2}{*}{ Metals } & \multicolumn{2}{|c|}{$\mathrm{HM}-\mathrm{F}$} & \multicolumn{2}{|c|}{ MT-F } & \multicolumn{2}{|c|}{ LM-F } \\
\hline & $(\mu \mathrm{g})$ & $(\%)$ & $(\mu \mathrm{g})$ & $(\%)$ & $(\mu \mathrm{g})$ & $(\%)$ \\
\hline $\mathrm{Cd}$ & 0.677 & 44.7 & 0.086 & 5.7 & 0.751 & 49.6 \\
\hline $\mathrm{Cu}$ & 0.714 & 10.6 & 0.676 & 10.0 & 5.35 & 79.4 \\
\hline $\mathrm{Zn}$ & 1.01 & 15.7 & n.d. & - & 5.41 & 84.3 \\
\hline
\end{tabular}

HM-F : High molecular weight protein fraction.

MT-F : Metallothionein fraction.

LM-F : Low molecular weight nonprotein fraction.

n.d. : None detected.

of cadmum were recovered from HM-F and LM-F. However, most of the urinary copper and zinc appeared in LM-F.

A gel filtration profile of the urine from another welder is shown in Fig. 5. The distribution patterns of the urinary metals were almost the same as those described above. MT-F also contained copper and cadmium, and the copper cotent of this fraction was larger than the cadmium content.

\section{Discussion}

In this paper, we have described the urinary excretion of cadmium, copper and zinc, and the gel chromatographic distribution of these urinary metals in welders who had been engaged in welding work with cadmium-containing silver solder for many years. The cadmium concentration in their work environment was reported previously by Toda et al..$^{13)}$ Other investigators ${ }^{14)}$ have indicated that metal fumes generated from this kind of silver solder contained zinc, silver and copper as well as cadmium. The cadmium content of the fumes reached about $85 \%$ of the total fume weight of these metals. These 


\section{$\mathrm{Cd}, \mathrm{Cu}$ AND $\mathrm{Zn}$ IN URINE OF WELDERS}

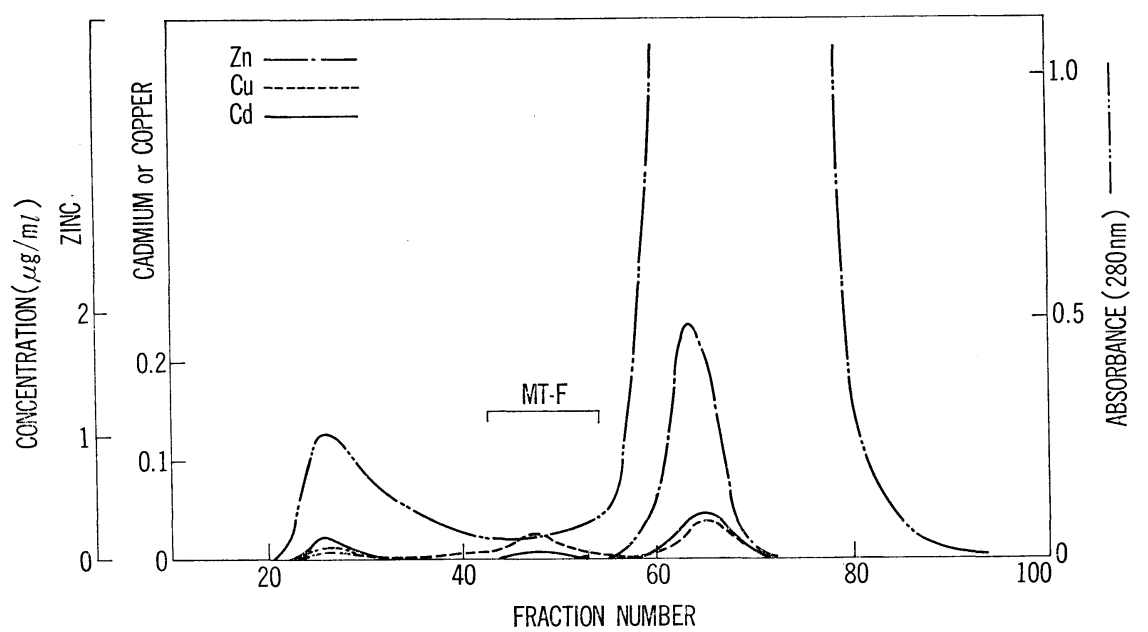

Fig. 5. Sephadex G-75 separation profile of urine from a worker who had been engaged in welding work using cadmium-containing silver solder for about 4 years. The urine $(100 \mathrm{ml})$ was concentrated by ultrafiltration with UM-2 up to about $10 \mathrm{~m} l$. The concentrated urine sample was filtrated on a Sephadex column $(2.6 \times 50 \mathrm{~cm})$ with $0.05 \mathrm{M} \mathrm{NaCl}$ and $0.01 \mathrm{M}$ Tris$\mathrm{HCl}$ buffer, $\mathrm{pH} 8.6$, containing $0.02 \%$ sodium azide at a speed of $20 \mathrm{ml} / \mathrm{hr}$, and $4 \mathrm{ml}$ fractions were collected.

data strongly suggest that the welders had been exposed to cadmium at the highest level and also to the other metals during their work. The present study was carried out at about one year after cessation of use of the cadmium-containing silver solder.

Nomiyama and Nomiyama ${ }^{15}$ ) have reported that the urinary excretion of cadmium decreased rapidly after cessation of cadmium exposure in rabbits. A similar phenomenon was observed in rats, but high excretion levels of urinary copper and zine continued after cessation of the cadmium exposure ${ }^{16)}$. The present data reveal that the urinary excretion of copper and zinc also maintained higher levels after cessation of cadium exposure in humans (Fig. 1). A linear relationship existed between the urinary concentrations of cadmium and both copper and zinc (Fig. 2). These findings suggest that cadmium accumulated in visceral organs affects the metabolic pathway of these essential metals over the long term without current exposure to cadmium.

Urine samples from two of the welders were subjected to Sephadex chromatography. It was suspected that the kidneys of these two workers had already suffered injury, on the basis of various clinical data including the urinary excretion of total protein, amino acids, glucose, retinol-binding protein and $\beta_{2}$-microglobulin, and PSP tests ${ }^{17)}$. In these samples, part of the urinary copper and cadmium was found in MT-F. The copper content of this fraction was much greater than that of cadmium. These metals were probably associated with urinary metallothionein. It has been reported by Suzuki and Yoshikawa $^{6}$ that metallothionein with similar metal-binding properties was excreted 


\section{Y. SUZUKI, K. TODA, S. KOIKE AND H. YOSHIKAWA}

in the urine of rats with cadmium-induced renal damage, although the urinary metallothionein was associated with only copper before the renal lesions had occurred. Shaikh and Hirayama ${ }^{4}$ have reported that cadmium-containing metallothionein was excreted in the urine of cadmium-exposed rats after renal damage had occurred. The present results demonstrate that human urinary metallothionein was associated with copper and cadmium, and suggest that the urinary excretion of metallothionein containing cadmium as well as copper my be involved in cadmium-induced renal injury in humans.

\section{REFERENCES}

1) Bonner, F.W., King, L.J. and Parke, D.V. (1979). Chem.-Biol. Interact., 27, 343.

2) Suzuki, Y. and Yoshikawa, H. (1981). J. Toxicol. Environ. Health, 8, 479.

3) Suzuki, Y. (1977). Jap. J. Ind. Health, 19, 200. (in Japanese).

4) Shaikh, Z.A. and Hirayama, K. (1979). Environ. Health Perspect., 28, 267.

5) Nordberg, G.F. and Piscator, M. (1972). Environ. Physiol. Biochem., 2, 37.

6) Suzuki, Y. (1980). Ind. Health, 18, 129.

7) Friberg, L., Piscator, M., Nordberg, G.F. and Kjellstrom, T. (1974). Cadmium in the Environment. Cleveland: CRC Press Division.

8) Lauwerys, R.R., Buchet, J.P. and Roels, H. (1976). Int. Arch. Occup. Environ. Health, 36, 275.

9) Lauwerys, R., Roles, H., Regniers, M., Buchet, J.P., Bernard, A. and Goret, A. (1979). Environ. Res., 20, 375.

10) Kono, S., Omura, T., Nakagawa, H., Toga, H., Nishi, M. and Matsuo, Y. (1980). Kankyo Hoken Repoto, 46, 248. (in Japanese).

11) Chang, C.C., Lauwerys, R., Bernard, A., Roels, H., Buchet, J.P. and Garvey, J.S. (1980). Environ. Res., 23, 422.

12) Berman, E. (1967). At. Absorpt. Newsletter, 6, 57.

13) Toda, K., Koike, S., Mori, Y., Sakuta, I., Shounaka, K., Ishiwata, K., Iwata, H. and Takada, Y. (1977). Jap. J. Ind. Health, 19, 381. (Proceedings of the 50th Annual Meeting of the Japan Association of Industrial Health, in Japanese).

14) Hara, N., Homma, K. and Koshi, K. (1968). Ind. Health, 6, 134.

15) Nomiyama, K. and Nomiyama, H. (1976). Effects and dose-response relationships of toxic metals, ed. G.F. Norberg, pp. 371. Amsterdam: Elsevier.

16) Suzuki, Y. unpublished data.

17) Toda, K., Koike, S., Mori, Y., Sakuta, I., Shounaka, K., Ishiwata, K., Iwata, H. and Takada, Y. (1977). Jap. J. Ind. Health, 19, 381. (Proceedings of the 50th Annual Meeting of the Japan Association of Industrial Health, in Japanese). 